\title{
A 5-year retrospective record review of hospital-based low-vision rehabilitation in Thailand
}

\author{
Suksri Chotikavanich \\ Nacha Chanvarapha \\ Siriwan Loket \\ Rungtip Yingyong \\ Somthin Dongngam \\ Waree Nujoi \\ Prapasson Sangsre \\ Krissana Maneephagaphan \\ Ketsara Rungsiri \\ Wichuda Krutthong
}

Department of Ophthalmology,

Faculty of Medicine, Siriraj Hospital,

Mahidol University, Bangkok, Thailand

Correspondence: Suksri Chotikavanich Department of Ophthalmology, Faculty of Medicine, Siriraj Hospital, Mahidol University, 2 Prannok Road, Bangkoknoi, Bangkok 10700, Thailand

Tel +6624198033

Fax +6624111906

Email suksri_c@yahoo.com
This article was published in the following Dove Press journal:

Clinical Optometry

Purpose: To investigate the quality-of-life-related goals of low-vision patients, the causes of visual impairment, and the low-vision rehabilitation services at a Thai national tertiary referral center.

Subjects and methods: A review was conducted on the medical records of patients attending the Low Vision Rehabilitation Clinic, Siriraj Hospital, Bangkok, Thailand, between 2012 and 2016. Results: A total of 992 patient records were included, comprising of 760 adults (aged over 15 years) and 232 children (aged $\leq 15$ ), with a mean age of 52.2 and 5.4 years, respectively. The retina was the most common anatomic site of visual impairment. Among the adults, the most common ocular condition was retinitis pigmentosa $(28.3 \%)$, followed by age-related macular degeneration (10.3\%), glaucoma (10.0\%), and diabetic retinopathy (9.6\%). As for the children, the most common ocular conditions were cortical visual impairment (17.7\%), optic nerve hypoplasia (13.4\%), and retinopathy of prematurity (9.5\%). More patients had low vision (a visual acuity of $<6 / 18-3 / 60$ ) than blindness (a visual acuity below $3 / 60$ ). The most commonly stated goals among the adults were reading, writing, and performing near tasks (34.7\%), and independent mobility $(21.3 \%)$, whereas for children, the most frequently indicated goal was visual and developmental stimulation (38.4\%). The services most often provided for the adults were the prescribing of visual aid devices $(51.8 \%)$ and orientation and mobility training (40.7\%), while the children most often received visual and developmental stimulation provided by a multidisciplinary team (33.8\%). The Thai Government's Universal Health Care Coverage scheme was the most commonly used medical insurance.

Conclusion: Data from this study can be used to improve low-vision patient care and rehabilitation services, and as input to the further development of national health care policies for low-vision patients.

Keywords: Thailand, low vision, vision rehabilitation, visual impairment

\section{Introduction}

Visual impairment is a major global health problem. The World Health Organization (WHO) has reported cataract and uncorrected refractive errors as the leading causes of low vision and blindness worldwide. ${ }^{1}$ In most cases, the two conditions are treatable disorders; nevertheless, in a low-vision rehabilitation setting, clinicians encounter irreversible eye problems with a range of impairments and causations. Incurable visual loss adversely impacts patients not only physically but also emotionally, vocationally, and socioeconomically, with families and society also bearing the burden of vision loss.

Low-vision services are needed to solve the problems. Information about the services around the world is scarce, but Chiang et $\mathrm{al}^{2}$ conducted a global survey of the 
services available in 195 countries during 2006-2008. They reported that the majority of people with low vision resided in developing countries, and that the coverage of services in Southeastern Asia was poor. Moreover, lack of government funding and awareness were barriers to the service access.

In the case of Thailand, a national policy for people with visual disability was developed early this decade. Accordingly, people who are certified with low vision or blindness by a Thai licensed physician are eligible to access many related resources, including low-vision rehabilitation services and assistive devices free of charge. As in many other countries around the world, those services are mainly provided in Thailand by the public sector; the private sector (mostly nonprofit organizations) provides the balance. ${ }^{3}$

The Thailand National Disability Survey of 2012 found that 404,141 Thais had a visual disability or visual handicap. ${ }^{4}$ That survey also revealed major problems regarding patient access to the government-provided resources, including services and equipment. A similar situation was reported in other countries, and to explain this, O'Connor et al suggested that differences in the service templates used by the various professions and institutions involved in delivering low-vision rehabilitation services may be a barrier to patient access to low-vision services. ${ }^{5}$ The organizations responsible for delivering those support services and resources include hospitals, schools for the blind, independent services for visually impaired individuals, government agencies of the Thai Ministry of Social Development and Human Security, and those government agencies of the Thai Ministry of Labor that assist visually impaired people to find employment in order to achieve financial independence. Other studies have shown that ophthalmologists were the primary referral source, with almost half of the clients referred by them. ${ }^{6,7}$ Gold et al also reported that the referrals between, and the level of effective cooperation among, the various resource centers were poor because of the practitioners who worked in the different agencies and organizations having limited awareness of the services available. ${ }^{7}$ Other barriers to individuals with visual disability not being able to access the resources included the assorted complications that come with not being able to see, including problems with transportation and obtaining information.

Unlike other service templates, a hospital-based rehabilitation service is the primary rehabilitation resource accessed after vision loss occurs. One strategy that might better respond to the objectives of the Thai national policy that barriers to service access be overcome is to integrate a wider range of resources into the hospital service template.
Under that approach, a continuum of care would be provided to patients, encompassing treatment, post-treatment rehabilitation, and cooperation with other related resources.

The objective of this study was to evaluate the causes of visual impairment among adult and pediatric patients attending a hospital-based, low-vision rehabilitation clinic. Moreover, this study also aimed to investigate other characteristics of the patients in terms of the severity of their visual impairment and their quality-of-life goals. All available services provided for pediatric and adult low-vision patients at the clinic were also reported. To the best of our knowledge and based on a review of the relevant English language literature (PubMed, ScienceDirect, Ovid, and Scopus databases), no previous study has reported the characteristics of patients at a low-vision rehabilitation clinic in a Thai hospital.

\section{Subjects and methods}

This 5-year, retrospective chart review was conducted at the Department of Ophthalmology, Faculty of Medicine, Siriraj Hospital, Mahidol University. There are $\sim 20$, hospital-based, low-vision clinics in Thailand. Siriraj Hospital is one of the five largest national tertiary referral centers providing low-vision clinics. The rest of the hospital-based low-vision clinics are in general hospitals scattered throughout the nation. No private hospitals or private clinics provide lowvision services.

The inclusion criteria for this study were all records of patients who attended the Low Vision Rehabilitation Clinic at Siriraj Hospital between 2012 and 2016. The retrospective period of 5 years was chosen because it would demonstrate the most current situation following changes earlier this decade in the government's national policies for people with visual disability, which required several years to be incorporated into clinical practice.

The protocol for this study was approved by the Committee for the Protection of Human Participants in Research at the Faculty of Medicine, Siriraj Hospital, Mahidol University, Bangkok, Thailand (Siriraj Ethics Committee number 462/2556[EC3]). This study complied with the principles set forth in the Declaration of Helsinki and its subsequent amendments. The ethics committee waived the need for informed consent because the research would not be feasible to carry out without the waiver, had important social value, and posed no more than minimal risks to participants. However, it was required that the confidentiality of patients' personal information be protected. To ensure accuracy and consistency of the data, all records were reviewed by only two clinical staff (SC and WK), with regular and ongoing communication, 
especially when conflicts arose. Moreover, the data collection form was simple, and the wording and sequence of each of its variables corresponded with those of the medical form in use at Siriraj's Low Vision Rehabilitation Clinic.

The clinic is staffed by one ophthalmologist, three rehabilitation teachers, four orientation and mobility (O\&M) instructors, and one social worker. The data were collected from both adult (aged over 15 years) and pediatric (aged 15 years or lower) patients. The age of 15 years was used because it corresponds with the patient age-group serviced by pediatric departments at most Thai hospitals; moreover, it corresponds with the age used in the definition of "youth" in Thai statutory law. During the study period, a total of 992 patient records were available for review, and all were included in the study. As the data reviewed related only to the condition of the better eye, the study was, therefore, based on 992 eyes. If a patient case had missing data for any one of the variables, then data relating to that variable for that patient were excluded from the analysis.

The cause of the visual impairment and the severity of the visual loss were evaluated. The impairment severity was classified according to the WHO classification criteria. ${ }^{8}$ To illustrate, the severity classification is determined relative to the visual acuity in the better eye, and it is grouped into five levels of visual impairment (level $1:<6 / 18-6 / 60$; level $2:<6 / 60-3 / 60$; level $3:<3 / 60-1 / 60$; level $4:<1 / 60$ to light perception; and level 5: no light perception), with the visual impairment then further categorized into "low vision" (a visual acuity of $<6 / 18-3 / 60$ ) or "blindness" (a visual acuity of $<3 / 60$ ). Visual field was the only variable missing in most records, making 257 records available for the review. The character of the visual field loss was reviewed according to the condition of the better eye. A visual field examination was unable to be carried out in patients with severe visual loss or blindness, or in patients with poor cooperation (such as very young children or very old adults). In addition, the activities the patients mainly wanted to achieve, or their goals to better their quality of life, were studied. All services provided for the patients at the clinic were also reported.

The government health insurance services that the patients used were also identified. In Thailand, there are three government health insurance programs. One is the "Civil Servant Medical Benefits Scheme" (CSMBS), provided for people who work for the government. Under this program, patients or their children can obtain reimbursement for the cost of medical care and devices. In addition, there is the "Social Security Fund and Worker's Compensation Fund" (SS), which covers costs for people who work for private companies. Finally, there is the "Universal Health Care Coverage Scheme" (UC) for all other Thai citizens (eg, those who run their own business). In the case of the SS and UC programs, patients are entitled to reimbursement only if they sought and received care at a hospital that collaborates with those health insurance schemes. This is challenging for people with visual disability given that independent mobility and financial problems are significant in this population. To solve this problem, the Thai government enacted a special disability health care privilege for people who are registered as being legally visually disabled. This program entitles patients to reimbursement for the cost of medical care, including rehabilitation services and optical aids, received at any government hospital or center in Thailand.

\section{Results \\ Characteristics of patients \\ Demographic data}

A total of 992 patients ( $48.8 \%$ male, $51.2 \%$ female), consisting of $760(76.6 \%)$ adults and $232(23.4 \%)$ children, were included in this study. The mean ages of the adult and pediatric patients were 52.2 (range 16-98) and 5.4 years (range $0.1-15)$, respectively.

\section{Causes of visual impairment}

The causes of visual impairment, categorized by anatomic site and ocular condition, are illustrated in Figures 1 and 2. The most common anatomic site of visual impairment for both adults and children was the retina. Retinal diseases affected about three-quarters of the adult patients $(70.3 \%$, 534 eyes) and $41.3 \%$ (100 eyes) of the pediatric patients. The next most common anatomic sites were the optic nerve ( $19.5 \%, 148$ eyes in adults and $24.1 \%, 56$ eyes in children) and the brain $(3.4 \%, 26$ eyes in adults and $17.7 \%, 41$ eyes in children).

Among the adult patients, the most common ocular condition was retinitis pigmentosa (RP; 28.3\%, 215 eyes), followed by age-related macular degeneration (AMD; 10.3\%, 78 eyes), glaucoma (10.0\%, 76 eyes), and diabetic retinopathy $(9.6 \%$, 73 eyes). As for children, the most common ocular conditions were cortical visual impairment (CVI; 17.7\%, 41 eyes), optic nerve hypoplasia (13.4\%, 31 eyes), and retinopathy of prematurity $(9.5 \%, 22$ eyes $)$.

\section{Severity of visual impairment}

Details of the severity of visual impairment in adult and pediatric patients are presented in Table 1. In the case of adults, more patients had low vision $(54.1 \%, 411$ eyes) than 


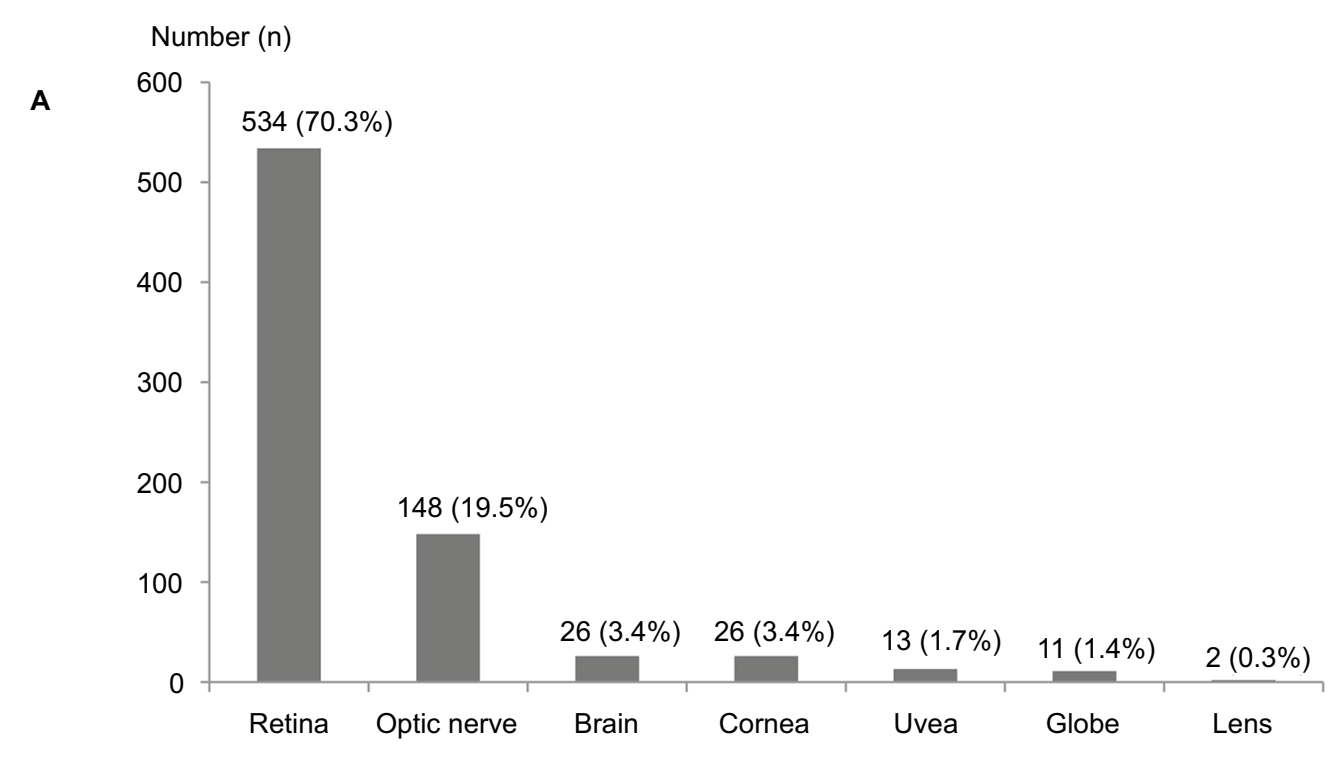

Number (n)

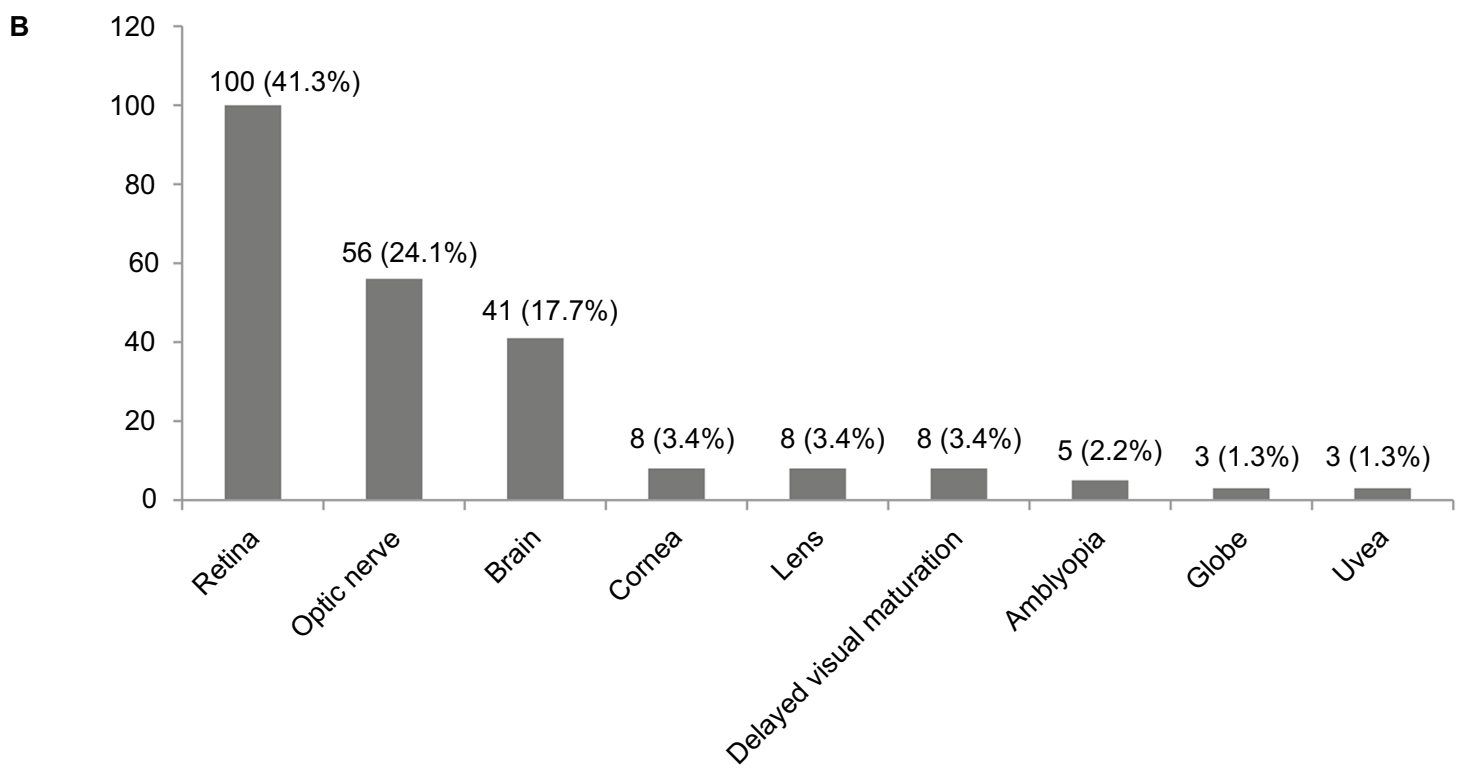

Figure I Causes of visual impairment categorized by anatomic site in (A) adult and (B) pediatric patients.

blindness $(15.4 \%, 208$ eyes). Almost half of the adults had a visual acuity of $<6 / 18-6 / 60$ (41.6\%, 316 eyes). Similarly, among school-aged children, there were more patients in the low-vision group $(23.6 \%, 55$ eyes $)$ than in the blindness group (14.8\%, 43 eyes). Fifteen percent (15\%, 35 eyes) had a visual acuity of <6/18-6/60 (15.0\%, 35 eyes). Among preschool-aged children, a preponderance was unable to fix and follow objects $(32.3 \%, 75$ eyes).

Of the 257 visual field records available, 236 were of adults and 21 were of children. Among the adults, 157 eyes
(66.5\%) had a visual field of $<30$ degrees, 51 (21.6\%) had a normal visual field or a visual field of $\geq 30$ degrees, and 28 (11.9\%) had central scotoma. Among the children, 13 eyes $(61.9 \%)$ had a visual field of $<30$ degrees, 5 (23.8\%) had a normal visual field or a visual field of $\geq 30$ degrees, and 3 (14.3\%) had central scotoma.

\section{Patient quality-of-life-related goals}

Visual impairment affects the lives of patients in different ways, and this was reflected in the range of responses received 
Number $(n)$

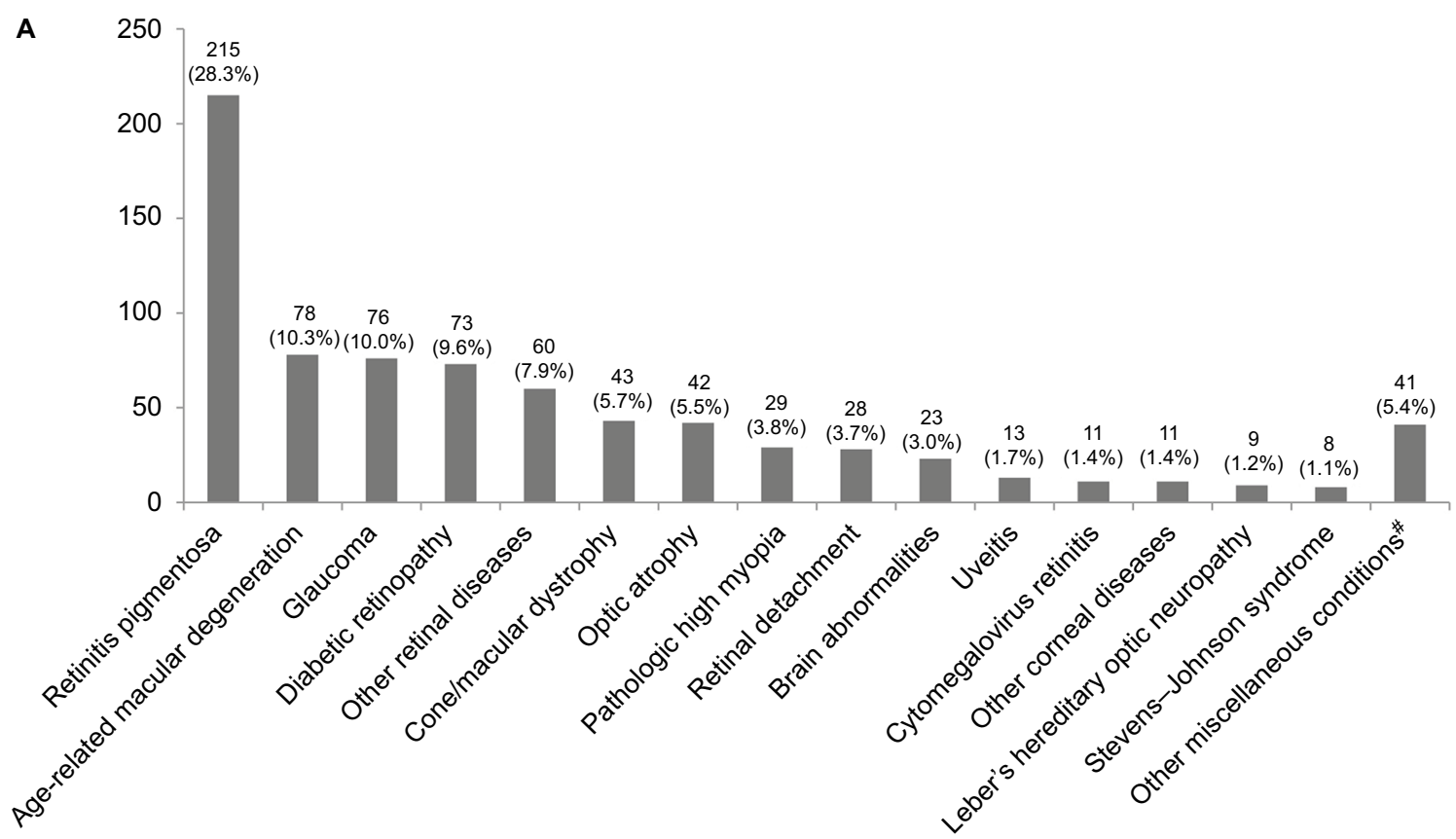

Number $(\mathrm{n})$

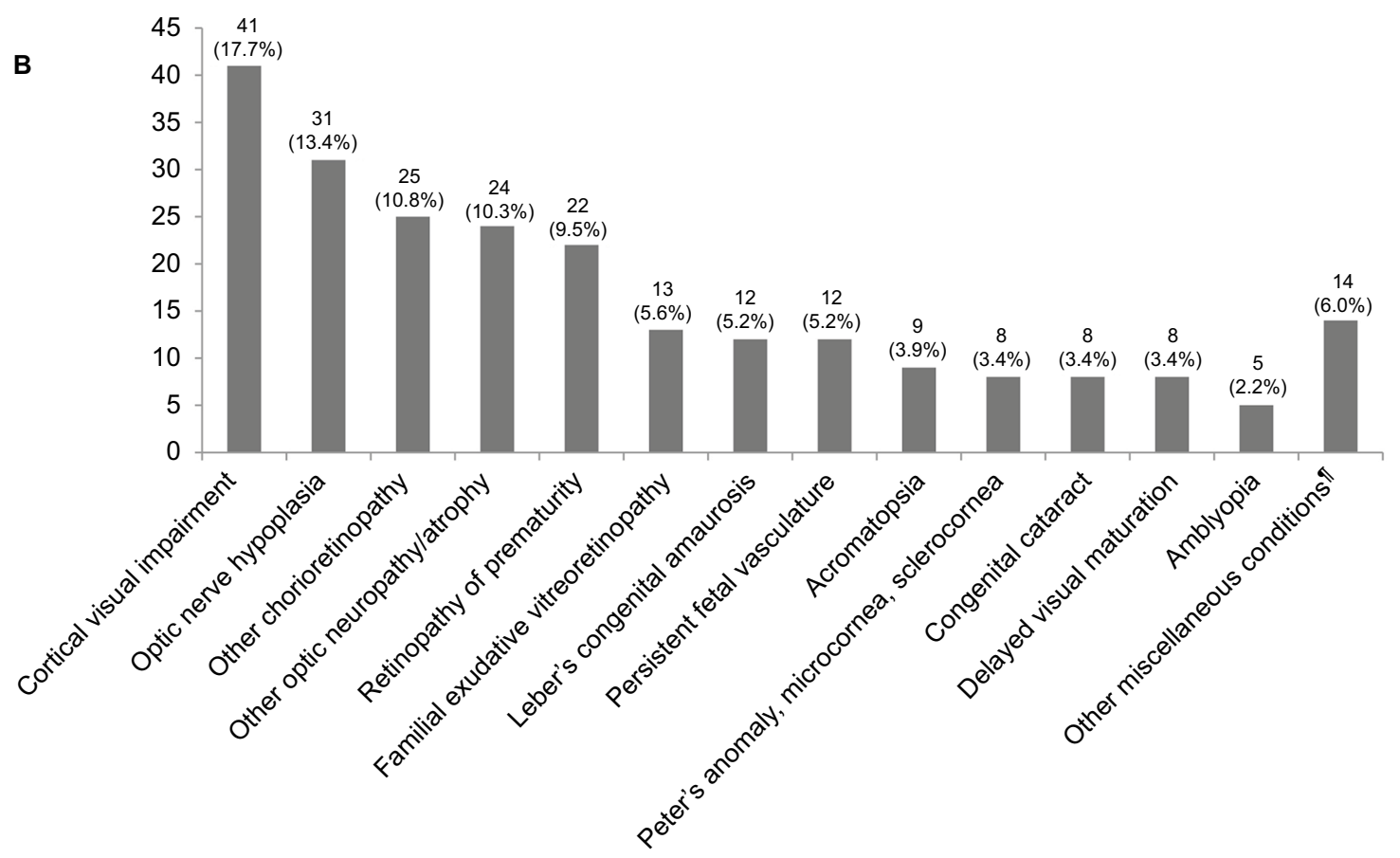

Figure 2 Causes of visual impairment categorized by ocular condition in (A) adult and (B) pediatric patients.

Notes: \#Other miscellaneous conditions (A) included traumatic/toxic/ischemic optic neuropathy, optic neuritis, microphthalmos, anophthalmos, anterior segment dysgenesis, phthisis bulbi, congenital cataract, congenital corneal disease, and bullous keratopathy. "Other miscellaneous conditions (B) included cone dystrophy, retinitis pigmentosa, microphthalmos, nanophthalmos, cryptophthalmos, uveitis, and glaucoma.

when patients were asked to describe their quality-of-liferelated, low-vision rehabilitation goals. These patient-stated goals, which appeared in their medical records as a part of the initial functional history-taking, were reviewed. The challenges and obstacles that patients sought to overcome are reflected in the list of goals in Table 2. A patient could respond with more than one goal of low-vision rehabilitation. Reading, writing, and performing a near task was the most commonly reported activity grouping among the adult patients (34.7\%, 503 eyes), followed by independent mobility and being registered for legal visual disability $(21.3 \%, 309$ eyes and 20.6\%, 299 eyes, respectively). It should be noted that 
Table I Severity of visual impairment of adult and pediatric patients

\begin{tabular}{llll}
\hline Visual acuity & $\begin{array}{l}\text { Vision status } \\
\text { classification }\end{array}$ & $\begin{array}{l}\text { Adults } \\
(\mathbf{n = 7 6 0 )}(\mathbf{1 0 0 \% )}\end{array}$ & $\begin{array}{l}\text { Children } \\
(\mathbf{n = 2 3 2}) \mathbf{( 1 0 0 \% )}\end{array}$ \\
\hline Equal to or more than 6/18 & - & $141(18.6 \%)$ & $10(4.3 \%)$ \\
Less than 6/18-6/60 & Low vision & $316(41.6 \%)$ & $35(15.0 \%)$ \\
Less than 6/60-3/60 & Low vision & $95(12.5 \%)$ & $20(8.6 \%)$ \\
Less than 3/60-1/60 & Blindness & $88(11.6 \%)$ & $27(11.6 \%)$ \\
Less than I/60-PL & Blindness & $103(13.6 \%)$ & $13(1.6 \%)$ \\
No PL & Blindness & $17(2.2 \%)$ & $3(1.6 \%)$ \\
Preschool children $(\mathbf{n = 1 2 4 )}$ & & & $47(20.2 \%)$ \\
Good fix and follow & & $\mathrm{N} / \mathrm{A}$ & $2(0.8 \%)$ \\
Poor fix and follow & & $\mathrm{N} / \mathrm{A}$ & $75(32.3 \%)$ \\
Not fix and follow & & $\mathrm{N} / \mathrm{A}$ &
\end{tabular}

Abbreviations: N/A, not applicable; PL, light perception.

Table 2 Quality-of-life-related goals of adults and children

\begin{tabular}{lll}
\hline Stated goals & $\begin{array}{l}\text { Adults } \\
(\mathbf{n}=\mathbf{I}, \mathbf{4 4 9 )} \\
\mathbf{( 1 0 0 \% )}\end{array}$ & $\begin{array}{l}\text { Children } \\
\mathbf{( n = 3 4 9 )} \\
\mathbf{( 1 0 0 \% )}\end{array}$ \\
\hline Reading, writing, near tasks & $503(34.7 \%)$ & $65(18.6 \%)$ \\
Distance identification & $58(4.0 \%)$ & $16(4.6 \%)$ \\
Independent mobility & $309(21.3 \%)$ & $15(4.3 \%)$ \\
Self-care, domestic activity & $144(9.9 \%)$ & $14(4.0 \%)$ \\
Social well-being & $52(3.6 \%)$ & $11(3.2 \%)$ \\
Mental adjustment & $41(2.8 \%)$ & $0(0.0 \%)$ \\
Occupation & $31(2.1 \%)$ & $1(0.3 \%)$ \\
Education & $12(0.8 \%)$ & $58(16.6 \%)$ \\
Visual and developmental stimulation & $0(0.0 \%)$ & $134(38.4 \%)$ \\
Registering for legal visual disability & $299(20.6 \%)$ & $35(10.0 \%)$ \\
\hline
\end{tabular}

there were notations in the charts of some eligible patients that indicated that they wanted to remain unregistered in an attempt to keep their vision disability concealed. For example, some patients felt that exposure of their disability would place their job at risk. Among children, the most common goal was visual and developmental stimulation (38.4\%, 134 eyes), followed by reading activities and educational rehabilitation (18.6\%, 65 eyes and $16.6 \%, 58$ eyes, respectively).

\section{Low-vision rehabilitation services}

All services provided for adult and pediatric patients at the Low Vision Rehabilitation Clinic at Siriraj Hospital are outlined in Table 3 . Among adults, the most common service provided was the prescribing of visual aid devices $(51.8 \%$, 436 eyes). The large majority of the devices prescribed were glasses (distance and/or near) and handheld magnifiers. Other devices prescribed included stand magnifiers, telescopes (distance), and electronic video magnifiers. Electronic video magnifiers and closed-circuit television systems were the only devices that were not free of charge for legally visually disabled patients. Even though these devices were available in desktop and portable (pocket-size) models, patients only purchased the portable models. Patients received appropriate training for any device that was prescribed or purchased. O\&M training for independent mobility and transportation use, and training for other basic activities of daily living (ADL), including self-care and domestic activities, were also commonly provided $(40.7 \%, 343$ eyes $)$. A small proportion of patients $(7.5 \%, 63$ eyes) required referral, with most being referred for occupational rehabilitation at one of the training centers throughout the country. Another common reason for referral was to allow patients to receive O\&M and ADL activity training at the local center servicing their hometown in another province.

In terms of services for children, the most common was visual and developmental stimulation (33.8\%, 125 eyes). Such stimulation was always performed at the center by a multidisciplinary team comprising an ophthalmologist, a pediatrician, and a pediatric rehabilitation doctor. Other services for pediatric patients included the provision of visual aid devices (25.1\%, 93 eyes), and O\&M and other basic ADL activity training (5.4\%, 20 eyes). Some children $(9.5 \%, 35$ eyes) were referred, mostly to receive visual and developmental stimulation at the center in or near their hometown; others were referred for educational rehabilitation at a primary or secondary school. The latter group of patients could have been enrolled in normal school classes or in a special program for children with disabilities at a school for the blind.

\section{Government health insurance support}

An overview of the government health insurance systems utilized by patients attending the Low Vision Rehabilitation Clinic at Siriraj Hospital is presented in Table 4. The UC had the preponderant coverage for both adult and pediatric patients, being used by 323 (42.5\%) adults and $133(57.3 \%)$ children. The CSMBS ranked second, supporting 211 $(27.8 \%)$ adults and $17(7.3 \%)$ children, while the disability 
Table 3 Services provided for adult and pediatric patients

\begin{tabular}{|c|c|c|}
\hline Provided services & $\begin{array}{l}\text { Adults } \\
(n=842)(100 \%)\end{array}$ & $\begin{array}{l}\text { Children } \\
(n=273)(100 \%)\end{array}$ \\
\hline Visual aid devices & $436(51.8 \%)$ & $93(25.1 \%)$ \\
\hline Orientation and mobility, self-care, and domestic activity training & $343(40.7 \%)$ & $20(5.4 \%)$ \\
\hline Referral & $63(7.5 \%)$ & $35(9.5 \%)$ \\
\hline Visual and developmental stimulation & $0(0.0 \%)$ & $125(33.8 \%)$ \\
\hline Type of device & $(n=436)(100 \%)$ & $(n=93)(100 \%)$ \\
\hline Glasses & $216(49.5 \%)$ & $33(35.5 \%)$ \\
\hline Handheld magnifier & $176(40.4 \%)$ & $24(25.8 \%)$ \\
\hline Stand magnifier & $19(4.4 \%)$ & $10(10.8 \%)$ \\
\hline Telescope & $15(3.4 \%)$ & $25(26.9 \%)$ \\
\hline Electronic video magnifier & $10(2.3 \%)$ & $\mathrm{I}(\mathrm{l} . \mathrm{l} \%)$ \\
\hline Referral for & $(n=63)(100 \%)$ & $(n=35)(100 \%)$ \\
\hline Orientation and mobility, self-care, and domestic activity training & $28(44.4 \%)$ & $7(20 \%)$ \\
\hline Occupation & $32(50.8 \%)$ & $0(0.0 \%)$ \\
\hline Education (primary, secondary school) & $\mathrm{I}(\mathrm{I} .6 \%)$ & $13(37.1 \%)$ \\
\hline Education (college, university) & $2(3.2 \%)$ & $0(0.0 \%)$ \\
\hline Visual or developmental stimulation & $0(0.0 \%)$ & $15(42.9 \%)$ \\
\hline
\end{tabular}

Table 4 Government health insurance utilization by adult and pediatric patients

\begin{tabular}{lll}
\hline Type of coverage & $\begin{array}{l}\text { Adults } \\
(\mathbf{n = 7 6 0 ) ( 1 0 0 \% )}\end{array}$ & $\begin{array}{l}\text { Children } \\
(\mathbf{n = 2 3 2})(\mathbf{1 0 0 \%})\end{array}$ \\
\hline Universal Health Care Coverage Scheme & $323(42.5 \%)$ & $133(57.3 \%)$ \\
Civil Servant Medical Benefits Scheme & $211(27.8 \%)$ & $17(7.3 \%)$ \\
Disability Health Privilege & $140(18.4 \%)$ & $82(35.3 \%)$ \\
Social Security Fund and Worker's Compensation Fund & $86(11.3 \%)$ & $0(0.0 \%)$ \\
\hline
\end{tabular}

health privilege system funded a marginally lower number of patients (140 [18.4\%] adults and 82 [35.3\%] children). The SS was utilized the least, servicing only $86(11.3 \%)$ adults.

\section{Discussion}

This 5-year review of 992 patients at a university-hospitalbased vision rehabilitation center in Thailand showed that the majority of the patients were adults. Of those, the most common anatomic site involved with the causation of visual impairment was the retina (70.3\%). This high proportion of retinal disease was consistent with the proportions reported by other studies. ${ }^{6,9-12}$ Regarding their ocular conditions, although AMD has been reported as the most common cause of visual impairment ( $40 \%-67 \%$ patients) by low-vision services in many countries, including Germany, ${ }^{9}$ the UK, ${ }^{10}$ Australia, ${ }^{11}$ and the USA, ${ }^{6} \mathrm{RP}$ was the most common cause of visual impairment in the current study (28.3\%), followed by AMD, glaucoma, and diabetic retinopathy for $10.3 \%, 10.0 \%$, and $9.6 \%$ of patients, respectively. The differences may be explained by a higher prevalence of AMD among Europeans than Asians, ${ }^{13}$ and a higher prevalence of RP in the Asian than the Caucasian population. ${ }^{14,15}$ Furthermore, the finding of a higher proportion of RP was consistent with another study, which found that RP was the most common cause of low vision at a Malaysian clinic, especially in the 30-59-year age group $(21.5 \%) .{ }^{16}$ Similarly, a Nigerian study reported RP to be the most common cause of low vision, but it was closely followed by AMD (16.6\% vs $14.5 \%) .{ }^{17}$ The high prevalence of RP at Siriraj Hospital's Low Vision Rehabilitation Clinic probably reflects a significant problem in Thailand that needs to be further investigated and addressed. However, the high number of RP cases found in the current study could be due to the fact that the Low Vision Rehabilitation Clinic is located in a tertiary referral center (namely, Siriraj Hospital), which receives complicated cases that are referred from other centers throughout Thailand.

With regard to the severity of visual impairment among the adult patients, more had low vision than blindness. This finding is consistent with a report from an Australian low-vision clinic. ${ }^{18}$ This study also found that patients with a visual acuity of more than $>6 / 18$ also sought help at our clinic. This meant that not only visual acuity, but also the loss of other visual functions, such as visual field or contrast sensitivity, contributed negatively to the functioning of patients.

Vision loss impacts patient activities and their quality of life in many ways. Among adults, reading, writing, and the 
performance of near tasks were the most often reported problems encountered by patients; those were also the most frequent at US and Australian centers. ${ }^{6,18}$ In particular, Owsley et al found that they were the most common problems at all types of low-vision practices in the US, including hospitals, government agencies, and private practices. ${ }^{6}$ Correspondingly, the most frequently provided service at Siriraj Hospital's Low Vision Rehabilitation Clinic was the prescribing of vision aid devices, of which the most usual were glasses, handheld magnifiers, and stand magnifiers. The cost of the devices was waived for patients with a Thai-registered legal visual disability. Telescopic devices to facilitate vision at a distance were prescribed in relatively low numbers. This may be because telescopes have a limited field of view and limited lighting, both of which make telescope-aided vision unsuitable or unattractive for patients with a restricted visual field, like patients with RP, glaucoma, or diabetic retinopathy. Moreover, patients with central scotoma, such as those with AMD, find it difficult to find and focus on objects when using a telescope. However, distance identification was only reported to be a problem by $4.0 \%$ of adults.

Among adults, the next most commonly reported qualityof-life-related goals of rehabilitation were independent mobility and domestic activity. Correspondingly, O\&M training and basic ADL training were the next most common services provided at the clinic. O\&M training is particularly useful for many patients, because traveling outside of familiar places is very challenging and this training improves their safety. At our center, O\&M training involved 80 hours of training divided into many separate training sessions. As there is no fixed protocol for such training, ${ }^{19}$ the courses, in terms of their training hours and session numbers, mobility aids, and environmental complexity scales, ${ }^{20}$ have varied among publications. ${ }^{19,21,22}$ For instance, studies from the Netherlands reported 3-hour training blocks divided into two sessions for partially sighted adults at the clients' home using an identification cane. ${ }^{19,21}$ Leat and Lovie-Kitchin from Australia constructed a course within their campus by designing walk-ways and obstacles. ${ }^{22}$ By comparison, in the present study, a long cane was the only mobility aid provided, and the training environment was both within the hospital campus and in the public spaces just outside the campus grounds. The cost of O\&M training is waived for people with a legal visual disability in Thailand. However, the cost of such training is usually not reimbursable by Medicare or private insurance in the USA. ${ }^{23}$

Patients who had transportation-related difficulty attending the O\&M sessions at Siriraj's Low Vision Rehabilitation
Clinic were referred to a local rehabilitation center near their hometown. Other reasons for referral included occupational training (eg, in the marketing of handicrafts, or in agricultural or computer skills) or an educational program. The majority of centers to which patients were referred waived all related costs for those patients with a registered legal visual disability.

Issues relating to problems with social well-being and mental adjustment were found among $6.4 \%$ of adult patients in this study. Rehabilitation counseling and group therapy services were provided, as appropriate. They allowed patients who shared common diseases and problems to share their experiences and problems, and the sessions encouraged the development of social relationships. It is also of value to note that increased emphasis has been given via changes to Thailand's national health and related policies to the minimization or elimination of the social exclusion experienced by those with disabilities, while enhancing their social inclusion. As well, the revised policies have heightened the focus on improving the access of people with low vision to health care, educational, and occupational services. In recognition of those policy changes, becoming registered as being legally visually disabled was often given as a quality-of-life-related goal by the visually impaired adults in the current study.

As for the children who attended the Low Vision Rehabilitation Clinic, the retina, optic nerve, and brain were the leading anatomic causes or sources of visual impairment. Even though less data on the patient characteristics of the pediatric low-vision population have been published than that for adults, the anatomic site findings of this study were similar to those reported by previous studies conducted in low-vision clinics in the UK, India, China, and Australia. ${ }^{24-27}$

However, there were variable findings in terms of the ocular conditions in the children who attended low-vision clinics in those previous studies. ${ }^{24-29}$ The variations depended not only on race and/or geographic location, but also on age distribution. In this study, the most common ocular condition among pediatric patients (aged between 0.1 and 15 years) at Siriraj's low-vision clinic was CVI (17.7\%), whereas optic nerve hypoplasia, retinopathy of prematurity, and other chorioretinopathy were less common. Once similarly aged pediatric patients were included, CVI was also found to be the most common ocular condition $(27 \%-45 \%)$ in other studies conducted in the Netherlands and the UK. ${ }^{28,29}$ Moreover, Boonstra et al identified a trend of change in the causes of low vision over the 21 -year duration of their study. ${ }^{28}$ They found a shift toward an increasing incidence of complex and untreatable diseases, like CVI, whereas more treatable disorders, 
like albinism, cone-rod retinal dystrophy, and cataracts, were observed less often (below 10\%). However, reports from other centers that included older children than those in the current study (ie, older than preschool age) showed hereditary macular degeneration to be the most common ocular condition. ${ }^{24-27}$ By way of example, a report from the $\mathrm{UK}^{24}$ showed that albinism (20\%) and cone-rod retinal dystrophy $(10 \%)$ were the most common. Reports from Australia ${ }^{27}$ and China $^{26}$ showed that congenital cataracts $(13 \%-21 \%)$, optic atrophy $(9 \%-14 \%)$, and macular dystrophy $(8 \%-11 \%)$ were the most frequent.

Even though eye globe diseases, such as microphthalmos and nanophthalmos, were found in only $1.3 \%$ of the pediatric patients in the present study, whole-globe disease was the most commonly reported cause of visual impairment at schools for the blind in many other reports, including from Thailand, the Philippines, and China, accounting for $25 \%$ $36 \%$ of cases among children. ${ }^{30-32}$ This may be explained by the hypothesis that a hospital-based low-vision clinic encounters more cases that do not present with an obvious, low-vision status or blindness, and those patients are more commonly referred to such hospitals for further management.

Considering the severity of visual impairment among the pediatric patients in this study, $32.2 \%$ of children of preschool age or younger were unable to fix and follow an object. This finding was consistent with the quality-of-life-related goal indicated by $38.4 \%$ of children that they needed visual and developmental stimulation. Because vision plays a vital role in stimulating and motivating children to explore their environment and achieve normal development (ie, motor, language, cognitive, and communication skills), a visual deficit is a major risk factor for delayed overall development. ${ }^{33}$ Moreover, comorbidity of visual and medical problems (eg, cerebral palsy) was observed in as many as $79 \%$ of children in a previous study. ${ }^{29}$ Given the potential for the development of vision-associated comorbidities, low-vision rehabilitation should involve a developmental team to supplement existing ophthalmic and pediatric services, and this intervention should be performed as early as possible..$^{29,33}$ To illustrate, a visual and developmental stimulation program should commence from when the child is an infant. ${ }^{34}$ Alimovic et $\mathrm{al}^{35}$ compared two groups of children with perinatal brain damage who were aged between 8 and 30 months, and aged within 8 months (range: $1-8$ months), and concluded that starting a visual stimulation program within the first 8 months of life resulted in a greater improvement in visual function. In this study, the Siriraj clinic's low-vision service for children younger than 5 years comprised a one-stop service team consisting of an ophthalmologist, a pediatrician, and a rehabilitation physician.

Regarding the severity of visual impairment among children older than preschool age in this study, more patients had low vision than blindness. Previous studies conducted at lowvision clinics in China, India, and Australia showed similar results. ${ }^{25-27}$ In contrast, studies conducted at schools for the blind in Thailand, the Philippines, and China reported higher proportions of blindness $(78 \%-95 \%)$ than low vision. ${ }^{31,32}$ This difference in findings may be because a certain percentage of low-vision students can attend and participate in classes at regular schools.

This study has some mentionable limitations. First, and consistent with the retrospective nature of this study, some patient data may have been missing or incomplete. In addition, the low-vision rehabilitation clinic which the study focused on is a tertiary referral hospital, which means that it receives relatively high numbers of referrals of patients with complicated and intransigent conditions. As such, it is possible that the study's findings may not be generalizable to patients with the same conditions in other settings. On the other hand, the strength of this study is that the data are representative of the predominant causes of low vision, patient quality-of-life-related goals, and the services provided in a relatively recent, real-world, low-vision rehabilitation setting.

In conclusion, because of the limited availability of low-vision services across Thailand, services provided at the secondary or the tertiary level, as suggested by $\mathrm{WHO},{ }^{36}$ should be integrated into government hospitals with an existing eye-care system that can be used as an accessible primary resource for low-vision patients. Knowledge of the types and magnitude of the service-related problems is essential to successfully provide the holistic and multidisciplinary care required of a rehabilitation service. ${ }^{3,37}$ This approach could also become a model template for other hospital-based services in Thailand. Furthermore, the information revealed by this study can be used to improve low-vision rehabilitation care and to further develop national health care policies as they relate to low-vision patients.

\section{Disclosure}

The authors report no conflicts of interest in this work.

\section{References}

1. Pascolini D, Mariotti SP. Global estimates of visual impairment: 2010 Br J Ophthalmol. 2012; 96:614-618.

2. Chiang PP, O'Connor PM, Le Mesurier RT, Keeffe JE. A global survey of low vision service provision. Ophthalmic Epidemiol. 2011;18: $109-121$. 
3. Markowitz SN. State-of-the-art: low vision rehabilitation. Can J Ophthalmol. 2016;51:59-66.

4. National Statistical Office Ministry of Information and Communication Technology. The 2012 Disability Survey. Bangkok: National Statistical Office Ministry of Information and Communication Technology; 2012.

5. O'Connor PM, Mu LC, Keeffe JE. Access and utilization of a new lowvision rehabilitation service. Clin Exp Ophthalmol. 2008;36:547-552.

6. Owsley C, McGwin G Jr, Lee PP, Wasserman N, Searcey K. Characteristics of low- vision rehabilitation services in the United States. Arch Ophthalmol. 2009;127:681-689.

7. Gold D, Zuvela B, Hodge WG. Perspectives on low vision service in Canada: a pilot study. Can J Ophthalmol. 2006;41:348-354.

8. World Health Organization. Chapter VII H54 Blindness and low vision. In: International Statistical Classification of Diseases, 10th Revision 2003 Version. 2nd ed. Geneva: World Health Organization; 2003.

9. Nguyen NX, Weismann M, Trauzettel-Klosinski S. Spectrum of ophthalmologic and social rehabilitation at the Tubinger Low-Vision Clinic: a retrospective analysis for 1999-2005. Ophthalmologe. 2008;105:563-569.

10. Pardhan S, Mahomed I. The clinical characteristics of Asian and Caucasian patients on Bradford's Low Vision Register. Eye (Lond). 2002; 16:572-576.

11. Chong MF, Jackson AJ, Wolffsohn JS, Bentley SA. An update on the characteristics of patients attending the Kooyong Low Vision Clinic. Clin Exp Optom. 2016;99:555-558.

12. Ramezani A, Pardis M, Rafati N, et al. Causes of visual impairment among patients referred to a visual rehabilitation clinic in Iran. Korean J Ophthalmol. 2012;26:80-83.

13. Wong WL, Su X, Li X, et al. Global prevalence of age-related macular degeneration and disease burden projection for 2020 and 2040: a systematic review and meta-analysis. Lancet Glob Health. 2014;2:e106-e116.

14. Zhang Q. Retinitis pigmentosa: progress and perspective. Asia Pac J Ophthalmol (Phila). 2016;5:265-271.

15. Chizzolini M, Galan A, Milan E, Sebastiani A, Costagliola C, Parmeggiani F. Good epidemiologic practice in retinitis pigmentosa: from phenotyping to biobanking. Curr Genomics. 2011;12:260-266.

16. Mohidin N, Yusoff S. Profile of a low vision clinic population. Clin Exp Optom. 1998;81:198-202.

17. Olusanya B, Onoja G, Ibraheem W, Bekibele C. Profile of patients presenting at a low vision clinic in a developing country. BMC Ophthalmol. 2012;12:31.

18. Wong EY, O'Connor P M, Keeffe JE. Establishing the service potential of secondary level low vision clinics. Optom Vis Sci. 2011;88:823-829.

19. Zijlstra GA, Ballemans J, Kempen GI. Orientation and mobility training for adults with low vision: a new standardized approach. Clin Rehabil. 2013;27(1):3-18.

20. Deverell L. O\&M environmental complexity scale. IJOM. 2011;4:64-77.

21. Ballemans J, Zijlstra GA, van Rens GH, Schouten JS, Kempen GI. Usefulness and acceptability of a standardised orientation and mobility training for partially-sighted older adults using an identification cane. BMC Health Serv Res. 2012;12:141.
22. Leat SJ, Lovie-Kitchin JE. Measuring mobility performance: experience gained in designing a mobility course. Clin Exp Optom. 2006:89:215-228.

23. Bowman EL, Liu L. Individuals with severely impaired vision can learn useful orientation and mobility skills in virtual streets and can use them to improve real street safety. PLoS One. 2017;12:e176534.

24. Lennon J, Harper R, Biswas S, Lloyd C. Paediatric low-vision assessment and management in a specialist clinic in the UK. Br JVis Impair. 2007;25:103-119.

25. Gothwal VK, Herse P. Characteristics of a paediatric low vision population in a private eye hospital in India. Ophthalmic Physiol Opt. 2000;20:212-219.

26. Gao G, Yu M, Dai J, et al. Demographic and clinical characteristics of a paediatric low vision population in a low vision clinic in China. Clin Exp Optom. 2016;99:274-279.

27. Kalloniatis M, Johnston AW. Visual characteristics of low vision children. Optom Vis Sci. 1990;67:38-48.

28. Boonstra N, Limburg H, Tijmes N, van Genderen M, Schuil J, van Nispen R. Changes in causes of low vision between 1988 and 2009 in a Dutch population of children. Acta Ophthalmol. 2012;90: $277-286$.

29. Flanagan N, Jackson A, Hill A. Visual impairment in childhood: insights from a community-based survey. Child Care Health Dev. 2003;29: 493-499.

30. Prabriputaloong A, Yospaiboon Y, Kittiponghansa S, Viwathanatepa $\mathrm{M}$, Sangveejit J. Causes of blindness and restoration of sight for the students in the School for the Blind, Khon Kaen. J Med Assoc Thai. 1989;72:606-612.

31. Gilbert C, Foster A. Causes of blindness in children attending four schools for the blind in Thailand and the Philippines. A comparison between urban and rural blind school populations. Int Ophthalmol. 1993;17:229-234.

32. Hornby SJ, Xiao Y, Gilbert CE, et al. Causes of childhood blindness in the People's Republic of China: results from 1131 blind school students in 18 provinces. Br J Ophthalmol. 1999;83:929-932.

33. Fazzia E, Signorinia SG, Bova SM, Ondeia P, Bianchi PE. Early intervention in visually impaired children. Int Congr Ser. 2005;1282: 117-121.

34. Kelley PA, Sanspree MJ, Davidson RC. Vision impairment in children and youth. In: Silverstone B, Lang M, Rosenthal B, Faye E, editors. The Lighthouse Handbook on Vision Impairment and Vision Rehabilitation. New York, NY, USA: Oxford University Press, Inc.; 2000:1137-1182.

35. Alimovic S, Katusic A, Mejaski-Bosnjak V. Visual stimulations' critical period in infants with perinatal brain damage. NeuroRehabilitation. 2013;33:251-255.

36. World Health Organization. Programme for the prevention of blindess and deafness. In: Proceedings of the Asia Pacific: regional low vision workshop, Hong Kong, 28-30 May 2001. Geneva: World Health Organization; 2002.

37. Markowitz SN. Principles of modern low vision rehabilitation. Can J Ophthalmol. 2006;41:289-312.
Clinical Optometry

\section{Publish your work in this journal}

Clinical Optometry is an international, peer-reviewed, open access journal publishing original research, basic science, clinical and epidemiological studies, reviews and evaluations on clinical optometry. All aspects of patient care are addressed within the journal as well as the practice of optometry including economic and business analyses. Basic and clinical Submit your manuscript here: https://www.dovepress.com/clinical-optometry-journal

\section{Dovepress}

research papers are published that cover all aspects of optics, refraction and its application to the theory and practice of optometry. The manuscript management system is completely online and includes a very quick and fair peer-review system, which is all easy to use. Visit http://www.dovepress. com/testimonials.php to read real quotes from published authors. 